\title{
Impacts of World Englishes on local standardized language proficiency testing in the Expanding Circle
}

\author{
QIUSI ZHANG
}

Purdue University

\section{A study on the College English Test (CET) in China}

\section{Introduction}

The world Englishes (WEs) paradigm describes the spread of English in three concentric circles (Kachru, 1985) - the Inner Circle (e.g., the USA, UK, and Australia), the Outer Circle (e.g. India, Philippines, and Singapore), and the Expanding Circle (e.g. China, Indonesia, and Thailand). With Englishization and nativization outside the Inner Circle and the changing demographics of English users (e.g. non-native speakers [NNSs] considerably outnumber the native speakers [NSs] in the Inner Circle [Crystal, 1995; Graddol, 1999], the WEs research strongly advocates to recognize the NNS varieties. Until today, the WEs paradigm has not only posed challenges to, but also encouraged changes in, the language testing (LT) profession that has been traditionally relying on the Inner Circle standard (e.g., Kachru, 1985; Lowenberg, 2002; Davies, Hamp-Lyons \& Kemp, 2003; Hu, 2012; Brown, 2014).

The discussion of the impacts of WEs on LT has been centered on standard/norm and consequent reliability and validity issues related to large-scale international standardized language proficiency tests (ISLPTs) that are developed and used in the Inner Circle; the conversation has also covered local standard language proficiency tests (LSLPTs) in the Outer Circle. However, locally developed and administered tests in the Expanding Circle context has been understudied, despite their growing impacts on the large population of users of English as a Foreign Language (EFL) (Lowenberg, 2002).

This study investigated to what extent LSLPTs in the Expanding Circle have been, and could further be, influenced by the WEs paradigm. By examining the College English Test (CET), one of the largest standardized English proficiency tests developed and administered locally in China, the study is believed to shed light onto the possible ways for negotiation and cooperation, instead of confrontation, between WEs and LT. The research will also extend the literature on WEs and LT in the Expanding Circle and 'broaden current

QIUSI ZHANG is a PhD
student in Second Language
Studies at Purdue University.
She is currently a testing
office assistant and tutor at
the Oral English Proficiency
Program (OEPP). Her past
work experiences include
teaching English as a foreign
language in China for four


understanding of the full range of users and uses of the [English] language' (Berns, 2005: 85).

\section{Literature review}

\section{World Englishes (WEs) and language testing (LT): The confrontation}

The tension between WEs and LT resides mainly on the standard/norm to use and the consequent reliability (or bias) and validity issues. In a nutshell, WEs criticizes LT for relying solely on the Inner Circle standard (e.g. Kachru, 1985; Lowenberg, 2002; Davies et al., 2003; Hu, 2012; Brown, 2014), or the two varieties - American and British English (Lowenberg, 2002; Hamp-Lyons \& Davies, 2008; Davies, 2009) used by educated NSs (e.g. Lowenberg, 1993, 2002; Davies et al., 2003; Jenkins, 2006), hence 'disconnect[ed] from the insights in analysis of English in the world context' (Davidson, 2006: 709). In addition, using the Inner Circle standard in an L2 test raises serious fairness concerns (e.g. Davies et al., 2003; Brown, 2004) such as discriminating against NNSs who typically have limited exposure (Kachru, 1985, 1992; Davies et al., 2003) or relevance (Canagarajah, 2006; Jenkins, 2006; Taylor, 2006) to this standard, misinterpreting 'deviations' as 'errors' (e.g. Kenkel \& Tucker, 1989; Lowenberg, 1993; Jenkins, 2006), etc. Further, the construct validity is questioned when an L2 assessment leaves out NNS varieties (e. g. Lowenberg, 1993; Brown, 2004; Canagarajah, 2006). Another issue related to construct validity is LT's tradition to have limited the definition of language proficiency to a monolithic construct that focuses on linguistic forms and correctness based on the NS standards (e.g. Matsuda, 2003; Canagarajah, 2006; Harding \& McNamara, 2018; Brown, 2020), despite the strong argument that English language proficiency is a multidimensional construct which also includes textual and pragmatic competence (e.g. Bachman, 1990; Bachman \& Palmer, 1996; Brown, 2020).

To such criticisms from the WEs research, LT researchers have rebutted with concerns regarding the importance of standard in testing (e.g. Lukmani, 2002; Davies, 2009), the insufficiency and inconsistency in codification of NNS varieties (e.g. Elder \& Davies, 2006; Davies, 2009), unacceptance from stakeholders (Davies et al., 2003; Brown, 2004, 2014, 2020; Taylor, 2006), as well as similar bias issues arouse with replacing the 'hegemony of the old with the hegemony of the new' (Berns, 2008: 333) and 'all the attendant consequences for those lacking the command of the new code' (Elder \& Davies, 2006: 296).
World Englishes (WEs) and language testing (LT): The negotiation and cooperation

Despite the tensions between WEs and LT, language testers are believed to have been 'responding to, not ignoring, WEs issues' (Brown, 2014: 12; Harding \& McNamara, 2018). Some tests, mostly ISLPTs that target candidates who intend to live and study in the Inner Circle, have taken a weak approach (Hu, 2012) and mainly accommodated to the NNS candidates without de-centering the Inner Circle standard (ibid; Elder \& Davies, 2006). For instance, the International English Language Testing System (IELTS) incorporated social and regional Inner Circle language variations into the reading and listening texts, used material writers from not only the U.K., but also Australia and New Zealand, and hired proficient NNSs as raters of the oral and written tests (Taylor, 2002). In addition, the Test of English as a Foreign Language (TOEFL) has explored L2 accents in listening assessment (Elder and Davies, 2006). Empirical studies on using proficient NNS raters in the test have also been conducted (e.g. Chalhoub-Deville \& Wigglesworth, 2005; Lazaraton, 2005; Hamp-Lyons \& Davies, 2008), which tend to suggest including NNS raters and training them to attend more to mutual intelligibility (e.g. Smith, 1992; Berns, 2008) and communicative effectiveness than NS grammatical competence (Matsuda, 2003; Taylor, 2006; Elder \& Harding, 2008; Brown, 2014; Harding \& McNamara, 2018) and only penalize errors that hinder communication (Taylor, 2006).

Others, especially English as a lingua franca (ELF) researchers, have practiced a stronger approach (Hu, 2012) that intends to take 'a new orientation towards the test construct' (ibid: 132). Manifestations of the strong moves can involve implementing new standard(s) (ibid; Elder \& Davies, 2006), such as EFL or local varieties that are considered as valid in their own right (Seidlhofer, 2001; Jenkins, Cogo, \& Dewey, 2011), or even a more thorough shift of the assessment focus from formal accuracy to communicative effectiveness. For instance, it is suggested to avoid discrete measures of linguistic forms (Canagarajah, 2006; Harding \& McNamara, 2018) and use performance-based assessment that simulates real-life communications in relevant contexts (Brutt-Griffler, 2005; Canagarajah, 2006; Elder \& Davies, 2006), such as paired tasks (e.g. Fulcher, 1996; O’Sullivan, 2002; Bonk, 2003). To this end, sampling should come directly from the local contexts, focusing on local topics and a diversity of NNS accents (Elder \& Davies, 2006); 
NNS interlocutors with different proficiency levels can be used to elicit strategic competence such as self-repair, speech accommodation, and meaning and difference negotiating, etc. (ibid). Although 'worth speculating' (ibid: 290), the strong approach faces challenges in practicality due to the dubious status (especially codification and acceptance by stakeholders) of the new norms.

\section{A less charted area: Local language testing in the Expanding Circle}

The conversation between WEs and LT has mainly revolved around large-scale ISLPTs developed and used mainly in the Inner Circle context (Criper \& Davies, 1988; Clapham, 1996). Even though research in international language (EIL) (e.g. McKay, 2002; Canagarajah, 2006; Schneider, 2011) and English as a lingua franca (ELF) (e.g. Seidlhofer, 2001; Jenkins, 2002, 2006; Elder \& Davies, 2006) have enriched the WEs research on testing outside the Inner Circle context, much more weight has been placed onto the Outer Circle than the Expanding Circle. Even in studies which cover both circles, much of the discussion arguing for the use of local norms in fact does not apply to the Expanding Circle given the premature stage of codification of local norms. As commented by Lowenberg (2002), there has been a lack of research on the LT in the Expanding Circle context, which holds 'the world's majority of English users' (p. 431).

Recent new understandings of the complex and dynamic community (Berns, 2005) demand more studies on the local language testing in the Expanding Circle. Originally regarded as normdependent (Kachru, 1985), the Expanding Circle has recently seen increasing use of English as a second language (ESL) in addition to English as a foreign language (EFL), for a mixture of international and intra-national purposes (Lowenberg, 2002; Berns, 2005; Canagarajah, 2006); there has also been growing discussion of local varieties in this context (e.g. Lowenberg, 2002; Canagarajah, 2006; Davies, 2009). Take China as an example. English in China today is used mainly as a global language in international, multicultural settings (Pan \& Block, 2011) for economic, social, cultural, and scientific communications (McArthur, LamMcArthur \& Fontaine, 2018). Besides, English is also used for intra-national purposes in specific domains such as medical, engineering, and media (Zhao \& Campbell, 1995). 'China English' (Ge, 1980), which refers to the educated variety (typically the English versions of Chinese idioms or slang), has begun to be considered a potential candidate for the standard English variety in China (Hu, 2004; Honna, 2020).

Very little research has closely studied the LSLPTs in Expanding Circle countries. Lowenberg's (2002) article titled 'Assessing World Englishes in the Expanding Circle' in fact examined the use of an ISLPT, the Test of English for International Communication (TOEIC), rather than LSLPTs in Expanding Circle countries such as South Korea, and China. Further, studies (e.g. Davidson, 2006; Elder \& Davies, 2006; Davies, 2009; Hu, 2012) that discuss local testing in the Expanding Circle are rather theoretical instead of data-driven. The only research that has been found to have investigated the local testing practice in the Expanding Circle is Davies et al. (2003), which reported findings from a seminar about the local English proficiency tests (i.e. NMET and CET) in China, among other tests in some Outer-circle countries. Davies et al.'s (2003) discussion was centered on the selection of contents/texts, scoring, and rater training of the CET in comparison to the TOEFL and concluded that the test practice in China is Inner Circle norm dependent and localized in selection of contents/ texts, scoring, and rater training; however, the conclusion was 'tentative' with no substantive examples or suggestions for changes.

\section{Present study}

This study conducted an in-depth analysis of a locally developed and administered language proficiency test in China - College English Test (CET). By examining the test specification and real test items delivered in the past three years (20172019), the data-driven study discusses how the ISLPT in the Expanding Circle has been assessing WEs and to what extent it can better incorporate the WEs paradigm. Research questions include:

1. What variety/varieties of English does the CET use?

2. How does the CET define language proficiency? Specifically, to what extent does the test assess NS linguistic forms and accuracy?

3. How can the CET better assess varieties of WEs?

\section{Method}

\section{The College English Test}

The College English Test (CET) is the 'largest English as a foreign language test in the world and one of the language tests that has attracted most public attention in China' (Zheng \& Cheng, 2008: 410). According to the latest version of the Test 
Specifications of the College English Test (National College English Testing Committee, 2016) (hereafter referred to as Specifications [2016]), the CET aims to assess general English proficiency and inform pedagogical improvement, graduate school admission, and employment in China. The CET consists of two tests - Band 4 and Band 6 - and is delivered semi-annually to college non-English majors who have completed two years and four years of the National College English Teaching Syllabuses (NCETS), respectively. Each band contains a written test (CET-4 and CET-6) and an oral test (CET-SET4 and CET-SET6). The written test comprises two selected-response sections, Listening and Reading, and two constructed-response sections, Writing and Translation. The SET is optional, but only for those who have passed a written test cutoff score. The delivery of the SET is automated, moderated by a computer examiner; tasks require both individual and paired work with a partner randomly assigned by the system. See Appendix I (Table 1-4) for the test structure.

\section{Data collection}

I conducted detailed analyses of two types of data: 1. the test specification, which provides a guideline for test construction and is crucial to test development (Davidson, 2006; Hu, 2012), and 2. test items, which indicate to what extent the blueprint is followed in practice rather than test writers' expertise knowledge (Davidson, 2006).

\section{Specification}

The latest version of the Specifications (2016) was downloaded from the CET official website: www. cet.edu.cn. ${ }^{1}$ It covers three parts: 1 . Descriptions of test purpose and use, structure, and rating criteria for the constructed sections; 2 . A vocabulary list; 3. A sample test for each level (Band 4 and 6), with sample answers for Writing and Translation. For this study, I analyzed the first and third part, which could reveal valuable information about how the test has defined the standard and construct in practice; the vocabulary list was reserved for future studies.

\section{Test item}

I examined the items in the 36 written tests ${ }^{2}$ delivered from 2017 to 2019 , accessible in two test preparation books (Wang, 2020a; Wang, 2020 b). Table 1 summarizes the counts of the analyzed test content by section. For convenience, citations of item sources will take such a form: CET4_06_17(1), denoting the first form of the

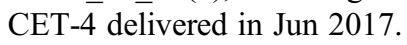

\section{Data analysis}

To answer the research questions, I first studied the test specification multiple times and marked wordings that could reflect the WEs paradigm. Informed by the literature review, my focus was on the statements of test purpose, question types, skills to be tested in each section, and rubrics of the Writing, Translation, and Speaking tasks. Next, I analyzed the two sample tests plus the 36 real tests (20172019), where I paid special attention to topic and content selection, context- or culture-specific information, accent in Listening, and the sample answers to Writing and Translation in the specification. Due to the large quantity of test items, I was able to record descriptive statistics about the characteristics (e.g. topic, sources, accent, genre) of the different sections, which help present the findings in a richer picture.

Regarding Listening and Reading, I coded each material in terms of topic, material sources, and accent in Listening (see Appendix II for sample coding). Concerning topic, I studied the material's estimated author, audience, and setting(s) based on the language and culture-specific elements (e.g. local companies and cultures) and then labeled each passage with one or more of the three broad categories - Inner Circle, Global, or Local (namely Chinese); within each topic category, I also coded

Table 1: Summary of Tests and Items in 2017-2019

\begin{tabular}{lcccccccc} 
Test & Year & Month & Form & $\begin{array}{c}\text { Tests }^{3} \\
\text { by } \\
\text { form }\end{array}$ & $\begin{array}{c}\text { Writing } \\
\text { prompts }\end{array}$ & $\begin{array}{c}\text { Listening } \\
\text { passages }\end{array}$ & $\begin{array}{c}\text { Reading } \\
\text { passages }\end{array}$ & $\begin{array}{c}\text { Translation } \\
\text { prompts }\end{array}$ \\
\hline CET-4 & $17-19$ & Jun/Dec & $1-3$ & 18 & 18 & 96 & 72 & 18 \\
\hline CET-6 & $17-19$ & Jun/Dec & $1-3$ & 18 & 18 & 844 & 72 & 18 \\
\hline Total & & & & 36 & 36 & 180 & 144 & 36 \\
\hline
\end{tabular}


specific countries or regions (as subcategories) if possible. Some passages could be identified with more than one (sub)category: for example, a listening passage about growing up in New Zealand and living in Asia would be labeled as 'IC(New Zealand)/Global(Asia)'. Regarding material sources, only reading materials could be traced, and I did this by googling and evaluating the content match between the material and the potential source. Given a lack of standards for identifying specific accents (e.g. American or British), accent was coded based on three broad categories, namely Inner Circle, Local/Chinese, and Others. Before analyzing the data, a second coder checked all the coding and resolved any deviations through discussions with me.

\section{Results and discussion}

\section{Research Question 1: What variety/varieties of English does the CET use?}

The study echoes Davies et al.'s (2003) main finding that the CET relies, although not consistently, on the Inner Circle standard. While topics and accents in the selected-response items are dependent on the Inner Circle context, global and local varieties have also been included, especially in the constructed-response tasks.

\section{Inner Circle varieties}

\section{Inner Circle topics in Listening and Reading}

As shown in Figure 1 and 2, most of the Listening and Reading materials in the CET could be related to the Inner Circle, especially US and UK. About $50 \%$ in Listening and $70 \%$ in Reading were identified as Inner Circle topics, among which US topics accounted dominantly for about $70 \%$ and $80 \%$ in Listening and Reading, respectively. UK topics ranked the second but accounted for a much smaller proportion. A few were relevant to other Inner Circle countries such as Canada, Australia, and New Zealand, but the percentage was rather negligible.

The Specifications (2016) designates 'original English-language materials' (p. 1) as the sources, which could partly explain the dominant percentage of Inner Circle topics. In fact, most sources of the reading texts could be traced to Inner Circle newspapers, magazines, and websites (see Figure 3), with the top sources being NPR News, Interesting Engineering, $B B C$, The Guardian, and The New York Times. Of course, some of the sources target a more global audience (e.g.

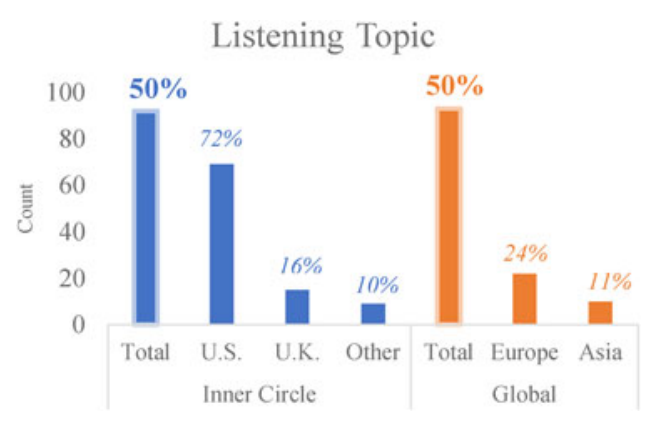

Figure 1. Topics in listening materials by region $(\mathrm{N}=180)$

Reading Topic

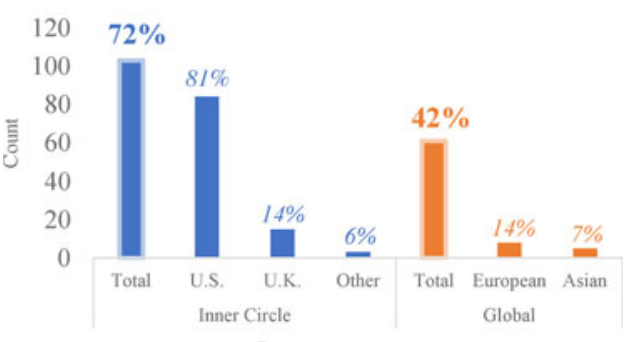

Figure 2 . Topics in reading materials by region $(\mathrm{N}=144)$

Interesting Engineering), but no local media sources were found.

The test's adaptation to the original sources mainly focused on text length and difficulty at the linguistic level, preserving the content and tone as addressing mainly the Inner Circle audience. Therefore, much content information could assume background knowledge. For instance, a reading passage (CET4_12_19[1]) opens with 'a polar wind brought bitter cold to the Midwest' without mentioning the 'Midwest' of which region, apparently composing for a local audience (in the US, which could be decided based on later message that contained regions and businesses in the country, e.g. Chicago, USPS, etc.). Many topics are hardly relevant to the Chinese culture and can be unfamiliar to Chinese test takers. For instance, a reading passage (CET4_12_18[1]) about healthy lifestyle discussed only Western dishes, such as cereal, frozen oranges and apples, and macaroni-and-cheese, which are rarely seen in the Chinese diet. Another example (CET4_12_19[2]) discusses the expensive E-textbook industry in the US, which can sound strange to the Chinese students who typically purchase paper books that are rarely found to be expensive. This unselective 


\section{Reading Source}

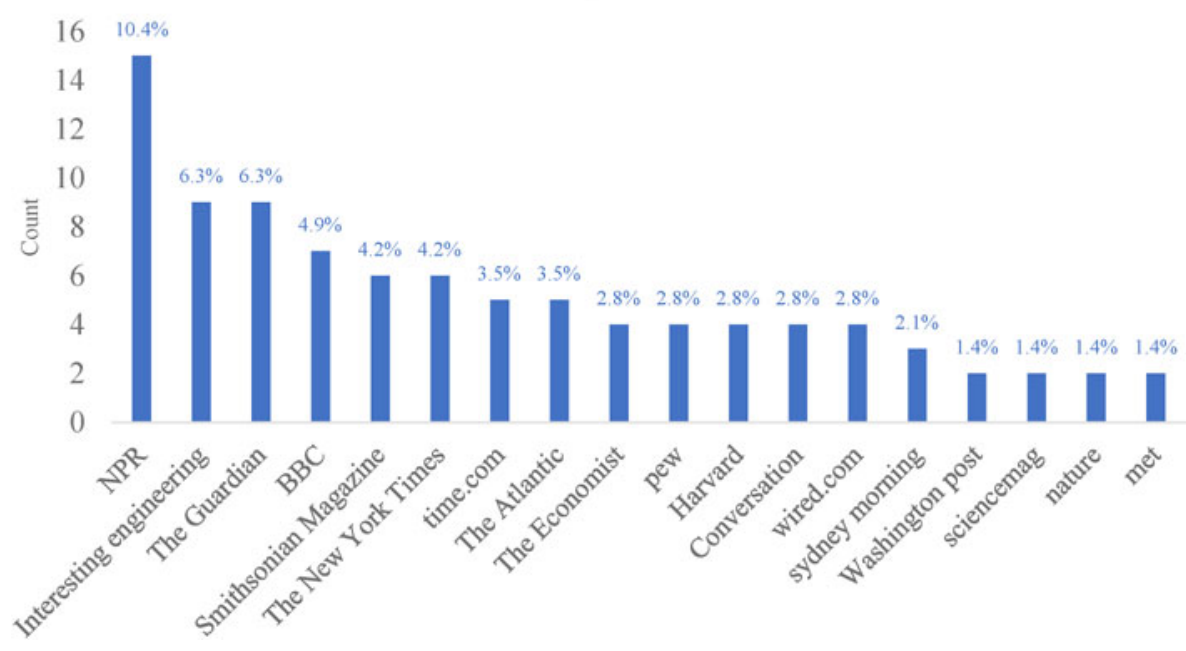

Figure 3. Sources of reading materials ${ }^{5}(N=144)$

adoption of original materials can lead to validity and bias concerns, which will be further discussed under Research Question 3.

\section{Inner Circle accents in Listening}

The Specifications (2016) openly states that the listening assessment 'uses standard American and British accents' (p. 6). This statement may not be easy to interpret, because in China, American and British English varieties are 'often mixed without distinction' (Davies et al., 2003: 577). Even when they are used in distinction, the definition of such standard accents can differ. In a narrow sense, they refer to the American and British accents spoken by educated NSs in the U.S. and U.K. In a broad sense, each may also contain other varieties in the Inner Circle; for instance, 'standard American accent' can also refer to educated Canadian accent and 'standard British accent' to educated Australian and New Zealand accents. Nevertheless, based on the test specification, it is obvious that the test is intended to use Inner Circle accents in Listening. An examination of the sample and real tests revealed that the listening test relied exclusively on varieties of Inner Circle accents, and no Chinese or other accents were identified.

\section{Global and local varieties}

\section{Listening and Reading}

Although relying on Inner Circle sources, the CET listening and reading passages also included topics related to global contexts (see Figures 1 and 2), particularly in CET-4. Specifically, 50\% $(\mathrm{n}=90)$ of the listening materials could be identified as global, with 22 passages situated in European settings (e.g. Italy and France), 5 in $\mathrm{Asia}^{6}$, and others undefined; $42 \%$ of the reading materials could be identified as global, with 8 passages situated in Europe, 5 in $\mathrm{Asia}^{7}$, and others unidentified. Although a small portion, it is worth noting that two topics involving Chinese culture were found in Reading - one (CET4_12_18[3]) discusses the writer's experience of having a Chinese medicine treatment in a China Town; the other (CET4_06_18[3]) is about Neon lights in Hong Kong. The statistics indicate that global topics in general account for a large percentage of the topics in Listening and Reading. Even though topic selection within the global category relies predominantly on European and other settings, the inclusion of global cultures that have more contact with China (e.g. Asian topics) as well as the local Chinese topics can serve as a good starting point and example for further diversifying topic selection.

\section{Writing}

Most of the writing prompts are, as found in Davies et al. (2003), similar with the TOEFL writing test (p. 578), which are mostly argumentative as shown in the following example (CET6_12_19[1]):

\section{(1) Write an essay on the importance of having a sense of social responsibility.}

However, I disagree with Davies et al. (2003) that the similarity signals dependence on the 
Inner Circle standard. Rather, such prompts do not assume any background knowledge related to any particular contexts and therefore show that the test is doing as fair a job as the TOEFL.

More importantly, a few prompts in more recent tests have attempted to include local elements, which has not been discussed in Davies et al. (2003), although, again, such prompts concentrated in the CET-4 tests. For instance, the three prompts in the CET4_12_19 set asked the examinees to recommend a place/city/university to a foreign friend. In CET4_06_19(2), the prompt states:

(2) Write a news report to your campus newspaper on a visit to a Hope elementary school organized by your Student Union.

The term 'Hope elementary school' refers to an elementary school built and supported by charitable contributions, which has strong Chinese characteristics and is representative of the local language variety, China English.

\section{Translation}

Translation does not typically occur in ISLPTs or even LSLPTs and therefore has rarely been discussed in prior literature. Interestingly, with the purpose to 'introduce the Chinese cultural, historical, and social development [to a foreign audience]' (Specifications, 2016: 4), the translation topics in both CET-4 and 6 were exclusively local. For example, many original Chinese texts were about the social development in China, such as Chinese family values (CET-4, Dec 2019), the use of mobile payment in China (CET-4, Dec 2018), the museums in China (CET-6, Dec 2018), etc. Prompts focusing on Chinese history and culture covered topics such as Chinese Lion Dance (CET4_06_19), famous mountains, rivers, and lakes (e.g. Mount Tai, CET4_12_17; Yellow River, CET4_06_17), and famous dynasties in history (e.g. Ming, Song, and Tang, CET6_06_17), to name just a few.

Some translation prompts also contained 'commonly used' (Specifications, 2016) Chinese idioms, such as 'ào rán zhàn fang' (proudly bloom ,meaning flowers blooming vibrantly) (CET6_12_19[1]) and 'chū wū ní ér bù răn' (out dirty mud but not polluted, meaning emerging pure and clean from the murky water, typically used to describe the characteristics of the lotus flower) (CET6_12_19[3]), and not surprisingly, culture-loaded names of historic figures, places, and events. Translating these idioms and terms requires a mastery of the educated local English variety, China English (Honna, 2020).
Research question 2: How does the CET define language proficiency? Specifically, to what extent does the test assess NS linguistic forms and accuracy?

The study examined the assessment goals, required skills, question types, scoring rubrics, and sample answers in the Specifications (2016) to gain an understanding of how the test defines language proficiency to be assessed. The examination reveals that the CET's assessment goal does not focus on NS linguistic forms and accuracy; rather, it emphasizes gauging overall communicative competence, regarding the local variety as acceptable and appropriate.

\section{Item types}

The CET does not contain discrete-point grammar items, which have been criticized by WEs scholars for focusing solely on NS linguistic forms and accuracy (e.g. Lowenberg, 2002; Matsuda, 2003; Canagarajah, 2006). Remarkably, Listening abandoned the task of 'Compound Dictation' (i.e. filling in blanks of a listening passage with words or phrases) (Li \& Zhao, 2016), or a listening cloze item, which has been questioned for being unable to assess high-order language abilities (e.g. Cohen, 1980; Buck, 2001; Cai, 2013). Avoiding such discrete-point grammar questions reflects the test's possible intention to deemphasize a specific standard or variety of English as the goal of assessment.

It is also worth noting that the SET contains paired interactions between Chinese test takers at different proficiency levels, which enables the elicitation of the examinees' interactive and negotiation skills through NNS-NNS communication (Canagarajah, 2006; Taylor, 2006; Harding \& McNamara, 2018). This reflects a strong move toward assessing WEs (Hu, 2012), especially when considering the possibility that, as Davies et al. (2003) indicated, raters of the CET are proficient English speakers with Chinese as their native language. Admittedly, it is challenging to conclude whose norms are actually referred to by the Chinese raters, and it needs further research to confirm whether such NNS rater recruitment still remains nowadays; however, the scoring criteria specified in the Specifications (2016) can speak to this issue and will be discussed in the following section.

\section{Scoring criteria}

An analysis of the scoring criteria (see Appendix III) of the constructed-response items (Writing, Speaking, and Translation) in the Specifications 
(2016) also suggests what the CET assesses is not centered on linguistic accuracy, but communicative competence at all linguistic levels (Berns, 2020). For instance, the rubric of the SET covers not only 'Accuracy and Range' at the grammatical level, but also Length and Coherence and 'Flexibility and Appropriateness' at the textual and pragmatic level. Specifically, the criteria of 'Flexibility and Appropriateness' refers to the abilities to 'respond to different situations and topics', 'participate in discussions actively', and 'adapt language use to different situations, functions, and purposes' (p.11-12), emphasizing the evaluation of candidates' competence in terms of functional effectiveness (Matsuda, 2003; Hu, 2012) and strategic competence (Jenkins, 2006; Jenkins et al., 2011, Hu, 2012), thus decentering the assessment of NS linguistic forms. As Elder and Davies (2006) pointed out, focusing the assessment on meaning making and functional effectiveness instead of language form enables a test to avoid the necessity for a description of which language norm(s) is the target, thus being considered a possible way to assess WEs or ELF.

Meanwhile, Elder and Davies (2006) raised the concern about what counts as an intelligible and successful conversation. Berns (2020) also claimed that communicative competence is an indispensable topic to WEs studies, and the key questions center around whose norms are considered acceptable, intelligible, and appropriate in different social contexts. An examination of the rubric descriptors and the translation and writing benchmarks in the Specifications (2016) indicates that there is no emphasis on the NS norms. For example, no reference was made to the 'native speaker' norms (Harding \& McNamara, 2018); instead, 'certain levels of native (Chinese) accent that don't affect intelligibility' (p .4) are not penalized in the SET; additionally, the rating of all constructed items allows for 'occasional minor errors' (p. 5), suggesting a likely intention to differentiate 'errors' from 'deviations' and acknowledgment of the local variety. The following CET-4 benchmark translation about traditional Chinese hospitality can help us better understand how the test defines 'minor errors' and thus 'intelligibility' and 'appropriateness':

(3) The traditional Chinese way of treating guests requires hosts to prepare abundant and various dishes, and make the guests unable to finish them all. The typical menu for a Chinese feast consists of a set of cold dishes, which are served at the beginning and some hot dishes after that, such as meat, chicken, ducks, and vegetables. In most feasts, a complete fish is considered necessary unless various kinds of seafood have been served. Nowadays, Chinese people like to mix western special dishes with traditional Chinese cuisine, so it is not rare to find steak on the table. In addition, salad has gained its popularity constantly, even though Chinese people are not likely to eat dishes that have not been cooked in tradition. There is generally a soup in a feast, which can be served at the beginning or the end of the meal. Besides, desserts and fruits often mark the end of a feast. (p. 200)

Although the underlined expressions are not idiomatic or 'correct' under the Inner Circle standard, the response is used as the benchmark for the highest level (score 14) of writing, which means the 'deviations' were treated as merely differences. This suggests that the test treats the local variety as, if not the norm, at least acceptable and intelligible. The same applies to the Writing sample response, where the essay receiving the perfect score (score 14) also contains expressions that may sound strange or incorrect to NSs, such as 'to hear such argument' and 'harmful for following reasons' (p. 197). Of course, more research needs to be conducted on how raters rate in real tests to deepen our understanding of their interpretation of intelligibility, appropriateness, and acceptability in actuality.

\section{Research Question 3: How can the CET better assess WEs?}

\section{What has been done}

Following the lead of ISLPTs, the CET has taken active moves, essentially the weak approach, to assess WEs by diversifying the sampling sources within the Inner Circle. Generally, the CET fits fairly into the context of local testing in China. As a norm-dependent Expanding Circle country, China has relied on the NS-model (e.g. Kirkpatrick, 2006) in English education at the tertiary level (He \& Zhang, 2010), which largely explains its dependence on the Inner Circle standards and echoes Hu's (2012) advocacy to 'make allowances for individual aspirations to Inner Circle Norms' (p. 138). Meanwhile, the CET has taken actions to meet its purpose of assessing general English abilities in a wide range of communication contexts (Specifications, 2016). For instance, it also includes global and local elements in its input texts and item prompts and decenters the evaluation of the NS linguistic forms and accuracy by emphasizing intelligibility and communicative effectiveness. Some stronger approaches were 
also utilized, such as the paired interaction in the SET which has the potential to assess NNS-NNS communicative and strategic competence. The accommodations respond to the changing role of English from a way to "[interact] with native speakers with a focus on understanding the customs, the cultural achievements' (Berns, 2005: 86) to a tool for a mixture of international and intranational purposes. The incorporation of global and local elements to the Inner Circle standards, or the Standard English plus method (Li, 2006), speaks to the test's local validity and reliability. The bias issue is also addressed when the assessment acknowledges the acceptability of the local variety and recognizes certain levels of 'differences' and 'deviations'.

\section{Recommendations}

The nature of WEs tends to favor pluralism, instead of a certain, single variety or group of varieties; therefore, it is important to make ways for diversity in assessment, to prepare the English learners in the Expanding Circle for real-life communications (Canagarajah, 2006; Hu, 2012). The following aspects of the CET should be further diversified.

The topics in Listening and Reading, as noted earlier, have been too restricted to the Inner Circle context. The local validity and authenticity of the test can be questioned when the topics and contents relate little to the culture the candidates are familiar with and do not assess students' use of English in real life (Lowenberg, 1993; Canagarajah, 2006). Besides, topic familiarity has been suggested to play a crucial role in L2 listening and reading comprehension (Markham \& Latham, 1987; Leeser, 2004), since background knowledge enables the audience to connect new information to existing knowledge (Anderson \& Lynch, 1988) and make inferences needed for a coherent mental representation of a text's content (e.g. Kintsch, 1988; van den Broek et al., 1999). Therefore, irrelevant topics can bias against the Chinese examinees who have limited exposure to the corresponding culture- or context-specific background knowledge. To better assess WEs, the test should not only diversify sampling within the Inner Circle, but it should also address the global and especially the local contexts. As mentioned earlier, among the 36 tests delivered within the three years, only two reading passages and no listening passages were situated specifically in the Chinese context. Creating space for one or two texts from the local setting in one test could be a good start to assessing WEs. Regarding global topics, test developers can also consider cultures that have more contact with China (e.g. South Korea, Japan, India, Thailand) rather than relying predominantly on European contexts.

Topic familiarity has also been proved to relate strongly with writing performance (e.g. HampLyons \& Mathias, 1994; Magno, 2008; Mahdavirad, 2016). However, the majority of writing prompts do not relate to any local topics. Besides, the very few topics involving local varieties are not updated (e.g. the 'Hope elementary school' topic). Therefore, the test needs to incorporate more local and updated topics to the writing prompts.

The accents used in Listening, although not confined to a single variety, have been restricted to the varieties in the Inner Circle. The test should expose the examinees to more varieties to 'foster their sociolinguistic awareness and sensitivity' ( $\mathrm{Hu}$, 2012: 136; Brown, 2004; Kachru, 2011). The local variety, Chinese accent, can be a fair candidate. Studies (e.g. Harding, 2012) have indicated that Chinese students could be advantaged when taking listening assessment recorded by proficient Chinese-accented speakers. Indeed, the CET testtakers typically have much and even more exposure to the Chinese accent (e.g. learning English with teachers who share their L1) than other accents (He \& Zhang, 2010).

A recommended way to diversify the topic and accent selection discussed above is sample more from local English media, such as China Central Television (CCTV)-News (a local English TV channel), and China Daily and Beijing Today Weekly (local English newspapers). Take China Daily (see http:/global.chinadaily.com.cn/) as an example. It covers a wide range of global (including the Inner Circle) and local topics (e.g. World, China, Technology, Business, Culture, Travel, and Sports) that are closely relevant to Chinese people. One of the latest articles from ChinaDaily-Opinion discussing a popular topic in China - 'Food waste is a shameful chronic disease' - can be a potential Reading material. Another hot topic - 'Should mukbanger, or Chibo be banned?' - could be adapted for the writing or speaking test, with a slight modification by adding a brief explanation of the term 'Mukbanger'. ${ }^{8}$ In addition, the newspaper uses a combination of NNS and NS journalists that compose for both global and local audiences and is a source of the local variety, China English.

\section{Conclusion}

As a local standardized language proficiency test (LSLPT) in China, the College English Test (CET) demonstrates impacts of the WEs paradigm 
from various aspects, which contributes largely to the conversation of WEs and LT. Given the timehonored concerns such as insufficient codification and stakeholders' unacceptance of any new varieties as well as the entrenched NS-model in English education in China, the CET still uses the Inner Circle Standard as the underlying standard and construct, which is shown in the reliance on Inner Circle topics and accents in the selected-response items. However, the test has relaxed this standard to a large extent, by including global and local elements in the selected-item materials, focusing on global and local topics in the constructed prompts, and decentering the assessment of NS formal accuracy by avoiding discrete-point items and emphasizing communicative competence at all linguistic levels in the scoring. Different from traditional LT practices, the test also references the local variety when defining intelligibility, acceptability, and appropriateness in its scoring criteria.

Concerning the limitations of the test under the WEs framework, the study also proposed possible modifications to the Listening, Reading, and Writing tests, namely sampling more from local English media to add diversity and relevance to topic and accent selection. The modifications will address the local validity and bias issues attached to the restriction to the Inner Circle context that has little relevance to the Chinese context and make the assessed construct more comprehensive.

Due to the scope of the study, more research can be done in the future. First, the study only examined the scoring rubrics and sample responses in the test specification; research on rater behavior based on real response data in the Writing, Translation, and Speaking assessments would inform us of how scoring practices are related to the WEs paradigm. Besides, it would be helpful to conduct a more elaborate text analysis on the linguistic features of the test input and the vocabulary list in the specification to learn more about the underlying linguistic norms in the test. Additionally, it would be interesting to examine other LSLPTs in China, such as the Test for English Majors (TEM) and National College Entrance Exam (NCEE), and similar LSPTs in other nations, such as the National English Ability Test (NEAT) in South Korea, to enhance our understanding of language testing in the Expanding Circle context.

Nevertheless, the study could shed light onto how LSLPTs like the CET in the Expanding Circle context can benefit from the WEs paradigm and in what ways such tests can incorporate the advocacies by the WEs research into practice to better serve its local examinees under the dynamic sociolinguistic reality. Of course, more research on WEs in general, especially data-driven empirical studies such as those sufficiently codifying the varieties in the three circles, need to be done (e.g. Davies et al., 2003; Brown, 2014) in order to lay a more solid foundation for the conversation with $\mathrm{LT}$ and to dissolve more practicality issues.

\section{Notes}

1 The document is only available in Chinese, so any quotes from the Specifications (2016) for discussion will be based on my translations and interpretations of the original Chinese text.

2 The spoken test (SET) items were not available, so they were not included in the analysis.

3 Both the CET-4 and 6 are delivered twice a year; each test there contains comparable forms often with similar topics but with different test items; therefore, I treated the different forms as separate tests.

4 Each CET-6 Listening assessment has only two forms instead of three; the CET-6 Listening is also different from the CET-4 Listening in that the former contains seven passages while the latter eight.

5 Only sources that were cited more than once are represented in the figure.

6 Two from CET4_12_18(1), the others from CET4 06 18(2), CET6_06_19(1), and CET6_06_18(2).

7 From CET4 12_19(3), CET4 06_19(3), CET4_12 18(3), CET4_06_18(3), and CET4_06_18(2).

8 Definition of 'Mukbanger' on the website: 'a livestreamed eating show where the host binge-eats... which went viral on Chinese social media. . . since the call to stop wasting food' (ChinaDaily)

\section{Acknowledgements}

I would like to express my sincere gratitude to Dr. Margie Berns (Purdue University) for her supervision of the study as the final project of her World Englishes course, her encouragement to send the paper to English Today for publication, and an insightful discussion on the revision of the paper. I also thank Zijie Wu (Purdue University) for his efforts in checking the coding of the data and a helpful discussion of improving the coding.

\section{References}

Anderson, A. \& Lynch, T. 1988. Listening. Oxford: Oxford University Press.

Bachman, L. F. 1990. Fundamental Considerations in Language Testing. Oxford: Oxford University Press.

Bachman, L. F. \& Palmer, A. S. 1996. Language Testing in Practice. Oxford: Oxford University Press. 
Berns, M. 2005. 'Expanding on the Expanding Circle: where do WE go from here?' World Englishes, 24(1), 85-93.

Berns, M. 2008. 'World Englishes, English as a lingua franca, and intelligibility.' World Englishes, 27(3-4), 327-334.

Berns, M. 2020. 'World Englishes and communicative competence.' In C. L. Nelson, Z. G. Proshina, \& D. R. Davis (eds.), The Handbook of World Englishes ( ${ }^{\text {nd }}$ edn.), Hoboken, NJ: Wiley-Blackwell, pp. 674-685.

Bonk, W. 2003. 'A many-facet Rasch analysis of the second language group oral discussion.' Language Testing, 20(1), 89-100.

Brown, J. D. 2004. 'What do we mean by bias, Englishes, Englishes in testing, and English language proficiency?' World Englishes, 23(2), 317-319.

Brown, J. D. 2014. 'The future of world Englishes in language testing.' Language Assessment Quarterly, 11(1), $5-26$.

Brown, J. D. 2020. 'World Englishes and international standardized English proficiency tests.' In C. L. Nelson, Z. G. Proshina, \& D. R. Davis (eds.), The Handbook of World Englishes (2 ${ }^{\text {nd }}$ edn.), Hoboken, NJ: WileyBlackwell, pp. 703-724.

Brutt-Griffler, J. 2005, September. Striving to be the Native Speaker. Paper presented at British Association of Applied Linguistics (BAAL) Conference, Bristol, UK.

Buck, G. 2001. Assessing Listening. Cambridge: Cambridge University Press.

Cai, H. 2013. 'Partial dictation as a measure of EFL listening proficiency: Evidence from confirmatory factor analysis.' Language Testing, 30(2), 177-199. https://doi.org/10. 1177/0265532212456833

Canagarajah, S. 2006. 'Changing communicative needs, revised assessment objectives: Testing English as an international language.' Language Assessment Quarterly: An International Journal, 3(3), 229-242.

Chalhoub-Deville, M. \& Wigglesworth, G. 2005. 'Rater judgment and English language speaking proficiency.' World Englishes, 24(3), 383-391.

Clapham, C. 1996: 'The development of IELTS: a study of the effect of background knowledge on reading comprehension'. Studies in Language Testing (Vol. 4). Cambridge: University of Cambridge Local Examinations Syndicate and Cambridge University Press.

Cohen, A. D. 1980. Testing Language Ability in the Classroom. Rowley, MA: Newbury House.

Criper, C. \& Davies, A. 1988. ELTS Validation Project Report. University of Cambridge, Local Examinations Syndicate.

Crystal, D. 1995. The Cambridge Encyclopedia of the English Language. Cambridge: Cambridge University Press.

Davidson, F. 2006. 'World Englishes and test construction.' In B. B. Kachru, Y. Kachru \& C. L. Nelson (eds.), The Handbook of World Englishes. Malden, MA: WileyBlackwell, pp. 709-717.

Davies, A. 2009. 'Assessing World Englishes.' Annual Review of Applied Linguistics, 29, 80-9.

Davies, A., Hamp-Lyons, L. \& Kemp, C. 2003. 'Whose norms? International proficiency tests in English.' World Englishes, 22(4), 571-584.

Elder, C. \& Davies, A. 2006. 'Assessing English as a lingua franca.' Annual Review of Applied Linguistics, 26, 282-304.

Elder, C. \& Harding, L. 2008. 'Language testing and English as an international language: Constraints and contributions.' Australian Review of Applied Linguistics, 31(3), 34.1-34.11.

Fulcher, G. 1996. 'Testing tasks: Issues in task design and the group oral.' Language Testing, 13, 23-51.

Ge, C. 1980. 'Mantan you han yi ying wenti [Random thoughts on some problems in Chinese-English translation].' Fanyi Tongxun (Chinese Translator's Journal), 2, 1-8.

Graddol, D. 1999. 'The decline of the native speaker.' AILA Review, 13, 57-68.

Hamp-Lyons, L. \& Mathias, S. P. 1994. 'Examining expert judgments of task difficulty on essay tests.' Journal of Second Language Writing, 3(1), 49-68.

Hamp-Lyons, L. \& Davies, A. 2008. 'The Englishes of English tests: Bias revisited.' World Englishes, 27(1), 26-39.

Harding, L. 2012. 'Accent, listening assessment and the potential for a shared-L1 advantage: A DIF perspective.' Language Testing, 29(2), 163-180.

Harding, L. \& McNamara, T. 2018. 'Language assessment: The challenge of ELF.' The Routledge Handbook of English as a Lingua Franca. Abingdon: Routledge, pp. 570-582.

He, D. \& Zhang, Q. 2010. 'Native speaker norms and China English: From the perspective of learners and teachers in China.' TESOL Quarterly, 44, 769-789. doi:10.5054/ tq. 2010.235995

Honna, N. 2020. 'East Asian Englishes.' In C. L. Nelson, Z. G. Proshina, \& D. R. Davis (eds.), The Handbook of World Englishes ( ${ }^{\text {nd }}$ edn.), Hoboken, NJ: Wiley-Blackwell, pp. 248-265.

Hu, G. 2004. 'Why China English should stand alongside British, American, and the other "World Englishes".' English Today, 20(2), 26-33.

Hu, G. 2012. 'Assessing English as an international language.' In L. Aslagoff, S. L. McKay, G. Hu \& W. A. Renandya (eds.), Principles and Practices for Teaching English as an International Language. New York: Routledge, pp.123-143.

Jenkins, J. 2002. 'A sociolinguistically based, empirically researched pronunciation syllabus for English as an international language.' Applied linguistics, 23(1), 83-103.

Jenkins, J. 2006. 'The spread of EIL: A testing time for testers.' ELT journal, 60(1), 42-50.

Jenkins, J., Cogo, A. \& Dewey, M. 2011. 'Review of developments in research into English as a lingua franca.' Language Teaching, 44(3), 281-315.

Kachru, B. B. 1985. 'Standards, codification, and sociolinguistic realism: The English language in the Outer Circle.' In R. Quirk \& H. G. Widdowson (eds.), English in the World: Teaching and Learning the Language and Literatures. Cambridge: Cambridge University Press, pp. $11-30$.

Kachru, B. B. (ed.) 1992. The Other Tongue: English across Cultures. Urbana: University of Illinois Press.

Kachru, Y. 2011. 'World Englishes: Contexts and relevance for language education.' In E. Hinkel (ed.), Handbook of Research in Second Language Teaching and Learning (Vol. 2). New York: Routledge, pp. 155-172.

Kenkel, J. M. \& Tucker, R. W. 1989. 'Evaluation of institutionalized varieties of English and its implications for placement and pedagogy.' World Englishes, 8(2), 201-214. 
Kintsch, W. 1988. 'The role of knowledge in discourse comprehension: A construction-integration model.' Psychological Review, 95, 163-182. doi:10.1037/ 0033-295X.95.2.163

Kirkpatrick, A. 2006. 'Which model of English: Native-speaker, nativized or lingua franca?' In R. Rubdy \& M. Saraceni (eds.), English in the World: Global Rules, Global Roles. London: Continuum, pp. 71-83.

Lazaraton, A. 2005, May. 'Non-native speakers as language assessors: Recent research and implications for assessment practice.' In Multilingualism and Assessment: Achieving Transparency, Assuring Quality, Sustaining Diversity - Proceedings of the ALTE Berlin Conference, pp. 296-309.

Leeser, M. J. 2004. 'The effects of topic familiarity, mode, and pausing on second language learners' comprehension and focus on form.' Studies in Second Language Acquisition, 26, 587-615.

Li, D. C. S. 2006. 'Problematizing empowerment: On the merits and demerits of non-native models of English in the EIL curriculum.' SOUTHEAST ASIA: A Multidisciplinary Journal, 6, 112-131.

Li, H. \& Zhao, Y. 2016. “回顾大学英语四六级六次改革 [Review of the six revision of the College English Test (Band 4 and 6)].' English Square, 5, 90-92

Lowenberg, P. H. 1993. 'Issues of validity in tests of English as a world language: Whose standards?' World Englishes, 12(1), 95-106.

Lowenberg, P. H. 2002. 'Assessing English proficiency in the expanding circle.' World Englishes, 21(3), 431-435.

Lukmani, Y. 2002. 'English in India: Assessment issues.' In Presentation at the Hong Kong Seminar.

Magno, C. 2008. 'Reading strategy, amount of writing, metacognition, metamemory, and apprehension as predictors of English written proficiency.' Asian EFL Journal, 29(2), 16-48.

Mahdavirad, F. 2016. 'The effect of personal familiar vs. impersonal less familiar topic on expository writing task performance.' Linguistics Journal, 10(1).

Markham, P. \& Latham, M. L. 1987. 'The influence of religion-specific background knowledge on the listening comprehension of adult second-language students.' Language Learning, 37, 157-170.

Matsuda, A. 2003. 'Incorporating world Englishes in teaching English as an international language.' Tesol Quarterly, 37(4), 719-729.
McArthur, T., Lam-McArthur, J. \& Fontaine, L. (eds.) 2018. Oxford Companion to the English Language Oxford: Oxford University Press.

McKay, S. L. 2002. Teaching English as an International Language. Oxford: Oxford University Press.

National College English Testing Committee. 2016. 全国大 学英语四六级考试大纲 (2016 Revised Version) [National CET Test Specifications: Band 4 and Band 6 (2016 Revised Version)]. http://www.cet.edu.cn. (Accessed August 20, 2020).

O'Sullivan, B. 2002. 'Learner acquaintanceship and oral proficiency test pair-task performance.' Language Testing, 19(3), 277-295.

Pan, L. \& Block, D. 2011. 'English as a "global language" in China: An investigation into learners' and teachers' language beliefs.' System, 39(3), 391-402.

Schneider, E. W. 2011. English Around the World. Cambridge, UK: Cambridge University Press.

Seidlhofer, B. 2001. 'Closing a conceptual gap: The case for a description of English as a lingua franca.' International Journal of Applied Linguistics, 11(2), 133-158.

Smith, L. E. 1992. 'Spread of English and issues of intelligibility.' The Other Tongue: English Across Cultures, 2, 75-90.

Taylor, L. 2002. 'Assessing learners' English: But whose/ which English(es).' Research Notes, 10, 18-20.

Taylor, L. 2006. 'The changing landscape of English: Implications for language assessment.' ELT Journal, 60 (1), 51-60.

Van den Broek, P., Young, M., Tzeng, Y. \& Linderholm, T. 1999. 'The landscape model of reading.' In I. H. van Oostendorp \& S. R. Goldman (eds.), The Construction of Mental Representations during Reading. Mahwah, NJ: Erlbaum, pp. 71-98.

Wang, K. 2020a. 星火英语黑旋风试卷全真试题+标准模 拟 (4级) [Sparks English Heixuanfeng Real Tests + Standard Mock Tests (CET-4)]. Shanghai: Shanghai Jiao Tong University Press.

Wang, K. 2020b. 星火英语黑旋风试卷全真试题+标准模 拟 (6级) [Sparks English Heixuanfeng Real Tests + Standard Mock Tests (CET-6)]. Shanghai: Shanghai Jiao Tong University Press.

Zhao, Y. \& Campbell, K. P. 1995. 'English in China.' Englishes, 14, 377-377.

Zheng, Y. \& Cheng, L. 2008. 'Test review: College English Test (CET) in China.' Language Testing, 25(3), 408-417. doi:10.1177/0265532208092433 
Appendix I: Structure of the College English Test (CET)

\begin{tabular}{|lllccr|}
\hline Table 1.1: CET-4 (Specifications, 2016: 5) & & & & \\
Sections & \multicolumn{1}{c|}{ Contents } & Question Types & \#Qs & Weights & Time \\
Writing & Writing & Short Essay & 1 & $15 \%$ & $30 \mathrm{~min}$ \\
\hline Listening & News Report & Multiple-Choice & 7 & $7 \%$ & $25 \mathrm{~min}$ \\
& Long Conversation & Multiple-Choice & 8 & $8 \%$ & \\
& Passage & Multiple-Choice & 10 & $20 \%$ & \\
\multirow{2}{*}{ Reading } & Vocabulary & Banked-Cloze & 10 & $5 \%$ & $40 \mathrm{~min}$ \\
& Long Passage & Matching & 10 & $10 \%$ & \\
& Close Reading & Multiple-Choice & 10 & $20 \%$ & \\
\cline { 2 - 3 } & Chinese-English translation & Passage Translation & 1 & $15 \%$ & $30 \mathrm{~min}$ \\
\hline \multirow{2}{*}{ Total } & & & 57 & $100 \%$ & $125 \mathrm{~min}$ \\
\hline
\end{tabular}

\begin{tabular}{|c|c|c|c|c|c|}
\hline Sections & Contents & Question Types & \#Qs & Weights & Time \\
\hline Writing & Writing & Short Essay & 1 & $15 \%$ & $30 \mathrm{~min}$ \\
\hline \multirow[t]{3}{*}{ Listening } & Long Conversation & Multiple-Choice & 8 & $8 \%$ & $25 \mathrm{~min}$ \\
\hline & Passage & Multiple-Choice & 7 & $7 \%$ & \\
\hline & Lecture/Talk & Multiple-Choice & 10 & $20 \%$ & \\
\hline \multirow[t]{3}{*}{ Reading } & Vocabulary & Banked-Cloze & 10 & $5 \%$ & $40 \mathrm{~min}$ \\
\hline & Long Passage & Matching & 10 & $10 \%$ & \\
\hline & Close Reading & Multiple-Choice & 10 & $20 \%$ & \\
\hline Translation & Chinese-English translation & Passage Translation & 1 & $15 \%$ & $30 \mathrm{~min}$ \\
\hline Total & & & 57 & $100 \%$ & $125 \mathrm{mir}$ \\
\hline
\end{tabular}




\begin{tabular}{|c|c|c|c|c|}
\hline Task & Task Name & Description of Task & $\begin{array}{l}\text { Preparation } \\
\text { Time }\end{array}$ & $\begin{array}{c}\text { Response Time (per } \\
\text { test taker) }\end{array}$ \\
\hline Warm-up & Self-Introduction & $\begin{array}{l}\text { Each of the test takers } \\
\text { introduce themselves } \\
\text { as directed by the } \\
\text { examiner }\end{array}$ & & 20 seconds (take turns) \\
\hline 1 & Read-Aloud & $\begin{array}{l}\text { Read aloud a short } \\
\text { (120-word) passage. }\end{array}$ & 45 seconds & $\begin{array}{l}1 \text { minute } \\
\text { (simultaneously) }\end{array}$ \\
\hline 2 & $\begin{array}{l}\text { Question and } \\
\text { Answer }\end{array}$ & $\begin{array}{l}\text { Answer } 2 \text { questions } \\
\text { based on the read-aloud } \\
\text { passage }\end{array}$ & & $\begin{array}{l}40 \text { seconds } \\
\text { (simultaneously; } 20 \\
\text { seconds for each } \\
\text { questions) }\end{array}$ \\
\hline 3 & $\begin{array}{l}\text { Individual } \\
\text { Presentation }\end{array}$ & Describe a picture; & 45 seconds & $\begin{array}{l}1 \text { minute } \\
\text { (simultaneously) }\end{array}$ \\
\hline 4 & Pair Work & $\begin{array}{l}\text { Task with the partner } \\
\text { about a topic }\end{array}$ & 1 minute & $\begin{array}{l}3 \text { minutes (together; } \\
\text { interactively) }\end{array}$ \\
\hline
\end{tabular}

\section{Table 1.4. CET-SET6 (Specifications, 2016: 9)}

\begin{tabular}{|c|c|c|c|c|}
\hline Task & Task Name & Description of Task & $\begin{array}{c}\text { Preparation } \\
\text { Time }\end{array}$ & $\begin{array}{c}\text { Response Time (per } \\
\text { test taker) }\end{array}$ \\
\hline 1 & $\begin{array}{l}\text { Self-Introduction and } \\
\text { Question and Answer }\end{array}$ & $\begin{array}{l}\text { Each of the test takers } \\
\text { introduce themselves and } \\
\text { answer questions about one } \\
\text { topic as directed by the } \\
\text { examiner }\end{array}$ & & $\begin{array}{l}\text { Self-introduction: } 20 \\
\text { seconds (take turns) } \\
\text { Q\&A: } 30 \text { seconds } \\
\text { (take turns) }\end{array}$ \\
\hline 2 & $\begin{array}{l}\text { Individual } \\
\text { Presentation and } \\
\text { group discussion }\end{array}$ & $\begin{array}{l}\text { Give a presentation about a } \\
\text { topic; discuss with partner } \\
\text { about a designated topic }\end{array}$ & 1 minute & $\begin{array}{l}\text { Individual } \\
\text { presentation: } 1 \text { minute } \\
\text { (take turns) } \\
\text { Group discussion: } 3 \\
\text { minutes (interactively) }\end{array}$ \\
\hline 3 & Question and Answer & $\begin{array}{l}\text { Answer a question asked by } \\
\text { the examiner }\end{array}$ & & $\begin{array}{l}45 \text { seconds } \\
\text { (altogether; take turns) }\end{array}$ \\
\hline
\end{tabular}




\section{Appendix II: Sample coding}

Table 2.1 Sample coding for the Listening Section

\begin{tabular}{|c|c|c|c|c|c|c|c|}
\hline Test & & Topic/content & Setting & Proof & Instruction & Passage & Question \\
\hline \multirow[t]{8}{*}{ CET4_12_18 (1) } & NR1 & $\begin{array}{l}\text { A woman entering a } \\
\text { snake while driving }\end{array}$ & IC(US) & 'an Arkansas woman...' & IC & IC & IC \\
\hline & NR2 & $\begin{array}{l}\text { Fast food is slowing } \\
\text { down }\end{array}$ & IC(US) & $\begin{array}{l}\text { All about American fast food } \\
\text { restaurants, McDonald's, Burger } \\
\text { King, Taco Bell. }\end{array}$ & & IC & IC \\
\hline & NR3 & $\begin{array}{l}\text { private mission outside of } \\
\text { Earth's orbit }\end{array}$ & IC(US)/Global & U.S. government; U.S. company & & IC & IC \\
\hline & $\mathrm{C} 1$ & Vacation in Thailand & $\begin{array}{l}\text { Global } \\
\text { (Asia-Thailand) }\end{array}$ & $\begin{array}{l}\text { experience in Thailand; but English } \\
\text { names for the two speakers - Sophia } \\
\text { and Bob }\end{array}$ & IC & IC \& IC & IC \\
\hline & $\mathrm{C} 2$ & A new gym in town & Global & English names & & IC \& IC & IC \\
\hline & P1 & $\begin{array}{l}\text { how to keep track of job } \\
\text { applications }\end{array}$ & IC(US)/Global & $\begin{array}{l}\text { recommends using Microsoft Excel, } \\
\text { google, gmail account, google } \\
\text { calendar, etc. }\end{array}$ & IC & IC & IC \\
\hline & P2 & $\begin{array}{l}\text { School is not the only } \\
\text { choice for children } \\
\text { education }\end{array}$ & IC(US) & $\begin{array}{l}\text { mentions "In Philadelphia and } \\
\text { Portland, Oregon" }\end{array}$ & & IC & IC \\
\hline & P3 & Dance in America & IC(US) & "Dance in America is everywhere". & & IC & IC \\
\hline
\end{tabular}

* NP - 'News Report'; C - 'Conversation'; P - 'Passage'; IC - 'Inner Circle'; 
Table 2.2: Sample coding for the Reading section

\begin{tabular}{|c|c|c|c|c|c|}
\hline Test & $P$ & $\begin{array}{l}\text { Topic/ } \\
\text { content }\end{array}$ & Source & Setting & Proof \\
\hline \multirow[t]{3}{*}{ CET4_12_19 (1) } & 1 & $\begin{array}{l}\text { Health risks } \\
\text { of plastic } \\
\text { bottle water }\end{array}$ & $\begin{array}{l}\text { traveller.com. } \\
\text { au }\end{array}$ & $\begin{array}{l}\text { IC(US/ } \\
\text { UK) }\end{array}$ & $\begin{array}{l}\text { Examples: US companies and } \\
\text { academy (SUNY, Nestle, } \\
\text { Coca-Cola); } \\
\text { Spelling: British (analysed, litre, } \\
\text { organisation) }\end{array}$ \\
\hline & 2 & $\begin{array}{l}\text { Quiet heroism } \\
\text { of mail } \\
\text { delivery }\end{array}$ & The Atlantic & IC(US) & $\begin{array}{l}\text { Opening sentence 'a polar wind } \\
\text { brough bitter cold to the Midwest' } \\
\text { Examples of locations: cities or } \\
\text { organizations in the U.S. }\end{array}$ \\
\hline & 3 & $\begin{array}{l}\text { Virtual } \\
\text { assistant }\end{array}$ & $\begin{array}{l}\text { interesting } \\
\text { engineering }\end{array}$ & IC(US) & $\begin{array}{l}\text { Examples: U.S. academy (Gorgia } \\
\text { Tech); format of date: April } 26\end{array}$ \\
\hline
\end{tabular}

* P - passage; IC - Inner Circle.

\section{Appendix III: Rubrics for constructed-response tasks}

\section{Table 3.1: Writing rubric (Specifications, 2016: 10)}

\begin{tabular}{ll} 
Scale & \multicolumn{1}{c}{ Descriptors } \\
$\mathbf{1 4}$ & $\begin{array}{l}\text { Focuses on topic; Expresses ideas clearly; Language use is coherent and cohesive; Has few linguistic } \\
\text { errors; Only has occasional minor errors. }\end{array}$ \\
\hline $\mathbf{1 1}$ & $\begin{array}{l}\text { Focuses on topic; Expresses ideas clearly; Language use is coherent and cohesive but has a small } \\
\text { number of linguistic errors. }\end{array}$ \\
\hline $\mathbf{5}$ & $\begin{array}{l}\text { Mostly Focuses on topic; there are places where ideas are not clearly conveyed; lacks coherence and } \\
\text { cohesion; has a large number of linguistic errors; some errors are serious. }\end{array}$ \\
Mostly Focuses on topic; ideas are not expressed clearly; very limited coherence and cohesion; has a \\
large number of serious linguistic errors. \\
$\begin{array}{l}\text { Is disorganized and unclear; language is broken; most of the sentences have linguistic errors and most } \\
\text { of the errors are serious. }\end{array}$
\end{tabular}

Table 3.2: Speaking rubric - human raters (Specifications, 2016: 11-12)

\begin{tabular}{|c|c|c|c|}
\hline Scale & Accuracy and Range & Length and Coherence & $\begin{array}{l}\text { Flexibility and } \\
\text { Appropriateness }\end{array}$ \\
\hline 5 & $\begin{array}{l}\text { Uses grammar and } \\
\text { vocabulary fairly; } \\
\text { Demonstrates rich vocabulary } \\
\text { and complex syntactic } \\
\text { structure; } \\
\text { Pronunciation is fair; has } \\
\text { some native (Chinese) accent } \\
\text { that do not affect } \\
\text { intelligibility }\end{array}$ & $\begin{array}{l}\text { Is able to speak at length; } \\
\text { language use is coherent and } \\
\text { cohesive; } \\
\text { Has occasional pauses when } \\
\text { organizing thoughts and } \\
\text { choosing vocabulary but they do } \\
\text { not affect communication }\end{array}$ & $\begin{array}{l}\text { Responds to different } \\
\text { situations and topics } \\
\text { excellently; } \\
\text { Participates in discussions } \\
\text { very actively; } \\
\text { Can adapt language use to } \\
\text { different situations, } \\
\text { functions, and purposes }\end{array}$ \\
\hline
\end{tabular}




\begin{tabular}{|c|c|c|c|}
\hline Scale & Accuracy and Range & Length and Coherence & $\begin{array}{l}\text { Flexibility and } \\
\text { Appropriateness }\end{array}$ \\
\hline 4 & $\begin{array}{l}\text { Has some errors in grammar } \\
\text { use and word choices, but } \\
\text { they do not seriously affect } \\
\text { communication; } \\
\text { Demonstrates fair diversity in } \\
\text { word choices; } \\
\text { Pronunciation is good }\end{array}$ & $\begin{array}{l}\text { Can conduct coherent talks, but } \\
\text { most are short; } \\
\text { Has frequent pauses when } \\
\text { organizing thoughts and } \\
\text { choosing words, which } \\
\text { sometimes affects } \\
\text { communication }\end{array}$ & $\begin{array}{l}\text { Responds to different } \\
\text { situations and topics without } \\
\text { too much difficulty; } \\
\text { Participates in discussions } \\
\text { fairly actively } \\
\text { Can adapt language use to } \\
\text { different situations, } \\
\text { functions, and purposes } \\
\text { fairly well; }\end{array}$ \\
\hline 3 & $\begin{array}{l}\text { Has errors in grammar use } \\
\text { and word choice that } \\
\text { occasionally affect } \\
\text { communication; } \\
\text { Has limited vocabulary and } \\
\text { rather simple syntactic } \\
\text { structure; } \\
\text { Has flaws in pronunciation, } \\
\text { which sometimes affects } \\
\text { communication }\end{array}$ & $\begin{array}{l}\text { Talks are short; } \\
\text { Has frequent and long pauses } \\
\text { when organizing thoughts and } \\
\text { choosing words which affects } \\
\text { communication, but can finish } \\
\text { the basic task }\end{array}$ & $\begin{array}{l}\text { Cannot participate in } \\
\text { discussions actively; } \\
\text { Sometimes fail to adapt to } \\
\text { the change in topic or } \\
\text { content }\end{array}$ \\
\hline 2 & $\begin{array}{l}\text { Has so many errors in } \\
\text { grammar use and word choice } \\
\text { that often stops } \\
\text { communication; } \\
\text { Affects communication } \\
\text { seriously due to a lack of } \\
\text { vocabulary and syntactic } \\
\text { structures; } \\
\text { Pronunciation is weak }\end{array}$ & $\begin{array}{l}\text { Talks are short and lack } \\
\text { coherence; } \\
\text { Can barely communicate }\end{array}$ & $\begin{array}{l}\text { Cannot participate in } \\
\text { discussions }\end{array}$ \\
\hline 1 & No description & No description & No description \\
\hline
\end{tabular}

\section{Table 3.3: Translation rubric (Specifications, 2016: 10-11)}

Scale $\begin{aligned} & \text { The translated text accurately conveys the meaning of the original text. The text is fluent, has a clear } \\ & \text { structure, uses vocabulary appropriate, and with few linguistic errors (occasional errors are allowed). }\end{aligned}$
$\begin{aligned} & \text { The translated text fairly conveys the meaning of the original text. The text has a fairly clear structure, } \\ & \text { the language is fairly cohesive and coherent, with a small number of linguistic errors }\end{aligned}$
$\mathbf{8} \quad \begin{aligned} & \text { The meaning of the original text is conveyed acceptably. Coherence of the translated text is acceptable, } \\ & \text { with a considerable number of linguistic errors, among which some are serious errors. }\end{aligned}$
$\mathbf{5} \quad \begin{aligned} & \text { The translated text only conveys the meaning of a small part of the original text. Coherence of the } \\ & \text { translated text is unacceptable, with a considerable number of serious linguistic errors. }\end{aligned}$
$\mathbf{2}$ Except for a few words or sentence, the translated text hardly convey the meaning in the original text.

